\title{
Effect of corporate social responsibility on consumer retention for FMCG industries: a deep learning analysis of professional students of Odisha
}

\author{
Santanu Kumar Das ${ }^{1,2}$
}

Received: 18 May 2021 / Accepted: 7 September 2021 / Published online: 16 October 2021

(c) The Author(s) 2021

\begin{abstract}
Corporate social responsibility (CSR) represents a form of international private business self-regulation that contributes to the social aims of a charitable, activist, or philanthropic nature through helping ethically based practices. The benefits from CSR like generating better public image, enhance in community support, enhance in market share, enhance in the satisfaction of the consumer, enhance in the exports, offering better quality services and products, and enhance in the productivity is not considered as the perception level consumers. This paper analyzes the effect of CSR activities on the fast moving consumer goods (FMCG) industries on the basis of the retention of the consumers of FMCG products. Initially, a questionnaire is prepared that consists of five categories. Each category is composed of more than ten questions. The information related to the questionnaire is obtained in the view of the professional students from Odisha. The customers are requested to fill the exact information as much as possible. Next, a higher-order statistical analysis is considered for realizing the behaviour of the categories. Additionally, the usage of deep learning called Optimized RNN (O-RNN) is used for predicting the customer retention in maintaining the CSR on FMCG industries. The improvement in the traditional RNN is done by optimizing the hidden neurons by the improved form of Sea Lion Optimization Algorithm (slno) called Modified slno (M-slno) with the intention of minimizing the error among the actual and the predicted outcome, hence it is called as O-RNN. The retention of the customers regarding the effect of CSR activities on FMCG companies and the benefits from CSR is investigated using the O-RNN prediction analysis against several traditional deep learning models as well as different statistical measures.
\end{abstract}

Keywords Corporate social responsibility · Consumer retention · Fast moving consumer goods · Optimized recurrent neural network · Modified Sea Lion Optimization Algorithm

\section{Introduction}

The traditional organization makes the employment and wealth, even if the society offers a peaceful environment for flourishing the business [1]. Nowadays, there exist numerous tasks that the organization has to perform for the society. These are composed of social, environmental, political, and financial tasks. These tasks are attained by the organization by implementing several procedures and policies via distinct

Santanu Kumar Das

santanu.das.kumar@gmail.com

1 Faculty of Management Studies, Gandhi Global Business Studies, Berhampur, Affiliated to Biju Patnaik University of Technology, Odisha, India

2 Department of Business Economics, Veer Bahadur Singh Purvanchal University, Jaunpur, Uttar Pradesh, India techniques. These tasks are achieved in the business by the corporate social responsibility (CSR) [2]. CSR is a broad group of programs, practices, and policies that are joined into decision-making processes, supply chains, and business operations. It consists of responsibility for the past, present, and future effects on business [3,4]. It will be a perfect start using the theoretical enhancement of applicable corporate practices for the developing countries and the emerging markets. In these days, companies expand their boundaries from origin to the evolving markets that are sometimes called as emerging markets [5]. Nowadays, the business environment varies in the relations of both the globalization trend and the competitive environment. The current globalization trend makes the firms to participate directly in a competitive environment in an efficient manner. It requires clearly described business practices that contain a sound concentration on the public markets [6]. 
Various terms can be employed for the purpose of interchanging with CSR [7]. These terms are the corporate responsibility, sustainability, corporate accountability, corporate citizenship, and business ethics. In the modern business policies, it is also called as the "corporate sustainability" or responsible competitiveness". CSR suffers from the issues that are linked to the workplace, market place, human rights, governance, environment, community investment, and business ethics. Moreover, CSR obtains commercial, ethical, legal, and several expectations that the society is holding for the business. In the simultaneous case, it also handles the requirement of the entire stakeholders. CSR is composed of broad number of stakeholders [8, 9]. The stakeholder of an organization is composed of investors, employees, consumers, insurers, lenders, regulators, intergovernmental bodies, business partners, non-governmental organizations, and shareholders. The organizations or companies cannot remain as the segregated economic entities that function in isolation from the wider society [10]. Moreover, numerous researchers confirm that organizations or firms cannot be viewed as private institutions but can be viewed as social institutions. The organizations are involved in several activities that denote their CSR initiatives or practices [11]. Few activities include awareness programs for eradicating several diseases, arranging counseling sessions, empowering women and promoting gender equality, eliminating poverty and extreme hunger, offering scholarship to the needy children, running NGOs/schools, education promotion through conducting educational camps, safeguarding the natural resources, and protecting the environment. Therefore, a socially responsible organization or enterprise not only cares its customers but also cares nation, local communities, dealers, suppliers, and employees [12].

Nowadays, the FMCG companies that are functioning their business worldwide have concentrated much on the public welfare-oriented activities with consideration of upholding their brands via interrelating them within the closest under privileged people $[13,14]$. The FMCG is one of the most exciting and stable industries. FMCG has higher profitability and better profit growth than the other companies. The goods are produced and distributed in a very short span of time. It considers their self fulfillment and the social responsibility. It also promotes the societal development, and hence the corporate consist of responsibilities in the dynamic world. CSR generates novelty, business prospects, and to obtain spirited benefit. Further, it also offers an entry to the business that contributes to the upliftment and continual progress of the poor villages. Thus, it has forecasted the situation of the Indian business, since the business units have concentrated better with the increasing business. Nowadays, the business organization is considered as the social institutions due to two reasons [15]. Initially, the business organizations function and exist inside a social structure. It is necessary to win the social acceptance for the purpose of surviving. In the second case, the business organizations must be socially responsible since they operate a broad influence on the lifestyle of the society. The business can only enhance if they handle better relationships with the entire stakeholders [16, 17]. These relations can be improved if the organization satisfies their commitment in the path of the stakeholder, and the consumer seems to be one among them. Therefore, the response, characteristics, and consumers views for organizing the CSR programs also act as a significant role. CSR influences consumers mainly through a set of variables, such as perceived value, trust, and commitment, which in turn results in an increase in satisfaction and loyalty of the consumers. Being a socially responsible company can enhance the company's image and build its brand. It also increases the employee morale and lead to higher productivity. CSR increases the positive relationships and the profits. It enhances the trust of the public. The lack of information and the customer awareness is the main challenge in the CSR. There is also a lack of communication and cooperation in CSR. The development of the profitable customer retention strategy is the main goal of the managers for competing successfully in the marketplace. High, medium or low loyalty can be determined via relationship strength, switching patterns and share of the customer's business. Conceptualisation, operationalisation, and measurement are critical challenges faced by the customer retention. In this paper, we plan to deal with the proper and effective analysis of CSR effect on FMCG sector for maintaining the customer retention, which is not yet discussed in any literal works.

The contribution of the paper is as follows:

- To investigate the effect of CSR activities on the FMCG industries based on the customer retention of FMCG products with the help of deep learning analysis, which is the first work yet discussed in this field.

- To predict the customer retention in maintaining the CSR on FMCG industries in the usage of deep learning called Optimized RNN (O-RNN).

- To minimize the RMSE on consumer retention for FMCG industries by optimizing its hidden neurons.

- To optimize the hidden neurons of the RNN using a newly proposed optimization algorithm called M-SLnO that can solve all kinds of multi-objective optimization problems and also saves much time.

- To confirm the betterment of the proposed method in terms of prediction analysis against several deep learning algorithms as well as statistical analysis using several higher-order measures.

This work is about the effect of CSR activities on the fast moving consumer goods (FMCG) industries on the basis of customer retention. This work is new to the research field and 
the descriptive observations about contexts into theoretical claims about the concepts are created by collecting several responses from different industries. It is very innovative one and also we suggested this model by introducing a novel method to analyze the customer's perception regarding the CSR impact on the FMCG companies based on new artificial intelligent models [18, 19].

The organization of the paper is arranged in the following manner: "Introduction" provides the introduction regarding the customer retention of CSR on FMCG industries. "Literature survey" gives the explanation of the customer retention on CSR towards the FMCG. "Proposed model of analysing CSR on FMCG industries" describes the proposed model of analysing CSR on FMCG industries. "Customer knowledge on CSR activities" describes the customer knowledge on CSR activities. The customer's prospective factors that remain as the bottlenecks for implementing the CSR activities are defined in "Customer's prospective factors that remain as the bottlenecks for implementing the CSR activities". "Customer's preference to FMCG brands with CSR activities based on company" explains the customer's preference to FMCG brands with CSR activities based on company. “Customer's views on impact of CSR on FMCG companies" portrays the customer's views on impact of CSR on FMCG companies. The customer's retention criteria in relation to CSR towards FMCG are given by 'Customer's retention criteria in relation to CSR towards FMCG". The deep learning impact on CSR activities is briefly given in "Deep learning impact on CSR activities". "Results and discussions" returns the results and discussions. "Conclusions" returns the conclusion.

\section{Literature survey}

\section{Related works}

In 2020, Ramu and Vethirajan [20] have evaluated the effect of CSR on the manufacturing of personal care products of fast moving consumer goods (FMCG) companies on the basis of the consumer perception. The effect was evaluated by identifying the consumer knowledge on CSR activities and various factors are considered while the preference is allocated to the FMCG brands. The activities of CSR and the extent of gains are perceived by the consumer. In 2014, Shilpa Shinde [21] has addressed the buying characteristics of the customer in the product of FMCG companies with consideration of the CSR programs. The data were gathered from the Suburb Mumbai and Mumbai region. The investigation was performed by considering the factors such as CSR awareness program within the consumer, consumer's attitude towards the program, and the product's performance according to the program. The CSR program has considered important effect on the buying behaviour of the consumer. It acted as an encouragement to the organizations that used the CSR programs for the requirements as a sustainability factor.

In 2009, Saeed Khan [22] has considered CSR initiatives or responsibilities by maintaining the entire issues of the stakeholder that consist of commercial, ethical, legal, and various expectations that the society composes for the business. In India, the CSR initiatives were used by majority of the companies. The main challenge for the FMCG companies was the decrease of packaging materials. These companies were performing work in the area of girl child care, women's empowerment, community welfare, education, health care, and environment. The companies such as Hindustan Unilever initiated the work on reducing the $\mathrm{CO} 2$. These company websites offered information regarding their CSR initiatives but it was not updated in a regular manner. The Karmayog Rating was employed for checking their performance on CSR. This rating provided better insight into the CSR ratings of the main Indian FMCG companies. The technique of computing the rating was also analyzed.

In 2017, Sanclemente-Téllez [23] has associated the CSR technique to the marketing by addressing a categorization of distinct theoretical perspectives, where the interrelation of the constructs occurred. It was significant for the marketing managers for applying the CSR-oriented activities that generated value for distinct stakeholders. The knowledge was advanced on CSR implementation in the marketing area via the empirical evidence. In 2016, Anjum Amin-Chaudhry [24] has highlighted the CSR journey that initiated from an "abstract concept" to the "expected business practice". It offered a meta-analysis of the significant CSR literature and also found 12 familiar themes that emerged in distinct periods. This was labelled in a chronological order that begun from 1920 to the till day for the understanding purpose. The literature was wide and it did not miss a clear description of the themes and times in the CSR discourse. It viewed numerous variations in the manner businesses while performing their operations. These themes were reflective of the CSR journey. It was much topical in the recent stakeholder scrutiny of the working business.

In 2019, Sundström and Hjelm-Lidholm [25] have widened the customer loyalty by considering the perspective of organizational human resource and also addressed a model and framework for constructing the human resource literature. Majority of the companies contained high employee turnover and were having the same challenge, since it was related with the training and recruiting costs. It described that the customer loyalty becomes a query of customer organization that revealed an external human resource. A practical contribution learned from the successful employee motivation and recruitment experiences when it was working and viewing with the customer loyalty. 
In 2016, Jaiswal and Gautam [26] have revealed the traditional literature that was present on CSR. The contribution of several CSR researches paved the way for enhancing the traditional CSR technique. Moreover, it also extended the several CSR initiatives that were considered by the two FMCG companies that were leading in India such as the Hindustan Unilever Limited and Dabur India Limited in distinct areas. In 2013, Schlegelmilch et al. [27] have described CPCSR and also proposed a measurement method. On the basis of qualitative data from interviews with consumers and managers, a CPCSR conceptualization was also proposed. Moreover, the validating, as well as model testing, was happened on three large quantitative data sets. The measurement scale, as well as the conceptualization, assisted the companies in demonstrating the CPCSR on the basis of their behaviour. It also maintained the managers in recognizing the drawbacks in communication and CSR engagement. It also focused on the implications in the future research and the marketing practice.

In 2020, Agrawal [28] has divided this study into three sections. The identification of the several dimensions of CSR in the FMCG companies was provided in the first section. In the second section, the process of the applied AHP (Analytic Hierarchy Process) Model was defined to assign the weights for the different dimensions of CSR. The third section was used to test the model developed using AHP. This study was performed on the basis of primary and secondary data. The developed model with the help of experts' opinions was successfully tested for the four surveyed companies of FMCG sector.

In 2009, Hanke [29] has proposed a conceptual framework which was provided based on the development of a company's CSR strategy. This framework has supported the measures and instruments to made difficult CSR process more manageable and visible. It has also supported the organizations to reflect their relationship to society, particularly with regard to the inconsistencies within the economic system. On the basis of conceptual framework, process was enabled to understand whether the engagement was more driven by legitimation or by sensemaking.

Overall, CSR is the practice of combining social and environmental goals to the business operations. It includes improving a company's brand, helping the control costs, attracting the top quality talent and facilitating the long-term financial success. FMCG business units are very sensible in enchanting the CSR projects and process them in their business practices. By delivering the socially responsible activities, the FMCG business concerns can increasing their money-making process and brand name as well as repay more to the society [20].

\section{Review}

CSR is a group of programs, practices, and policies that are combined into decision-making processes, supply chains, and business operations along the organization. But, depending on the geographic region, sector, and size the CSR focus of an organization may vary and leads to several issues. Some of the most important features and challenges are listed in Table 1. Consumer perception [20] is composed of organizations with their own technical proficiency, financial support, strategical planning, and human resource and it also has the capability to enhance the quality and society of life. But, quick social development in a limited amount of time cannot be achieved by joining the NGOs and corporate. Customers buying behaviour [21] offers various features like less reputational risks, ready for paying premium prices, and enhanced customer loyalty in crisis times and the CSR programs of the organizations are encouraged in a sustainability factor. Still, it does not include the relevant applications or theoretical contributions. Corporate social performance [22] responds to the local differences by considering the specific initiatives and the benefits are provided to the companies that results in society's positive contribution. Yet, the root causes are not considered by the programmes. Marketing strategy [23] enhances the organization's financial performance and the CSR concept offers valuable input to the relationship. But, the geographic contexts cannot apply this process and it is also damaged by the varying environment. Meta analysis of CSR literature [24] identified the reflective themes and vast variations are offered in the business conduct. Still, the CSR adoption is not explained in governments and corporations. Organizational human resource perspective [25] explains the critical constituents and their relations and also offers the conviction idea. The customer loyalty is also extended. Yet, the problems are not highlighted by identifying the feedback from the customers and the illustration/empirical testing of the conceptual model is not performed and mostly the customer is not viewed as a human resource. Exploration of existing literature [26] ensures the health care, women empowerment, environmental sustainability, sanitation, and rural development projects. The employment, gender equality, and education are also promoted and the hunger and poverty is also eradicated. But, it does not perform the empirical study on different industries or companies and the cross country comparison is also not performed. Also, the various industries such as insurance industry, health care industry, IT industry, and hotel industry, etc. are not being focused here. CPCSR [27] makes the scale to act as a key mediator of consumer behaviour outcomes and CSR and the perceptions and views of the consumers are also captured. Still, more stimulation is not concentrated in the marketing area. These challenges are motivated to introduce a novel method to ana- 
Table 1 Features and challenges of state-of-the-art consumer's perception regarding the CSR impact on the FMCG companies

\begin{tabular}{|c|c|c|}
\hline Author [citation] & Features & Challenges \\
\hline Ramu and Vethirajan [20] & $\begin{array}{l}\text { The company has the capability to enhance the } \\
\text { quality and society of life } \\
\text { The organizations are composed of their own } \\
\text { technical proficiency, financial support, } \\
\text { strategically planning, and human resource }\end{array}$ & $\begin{array}{l}\text { It does not join the NGOs and corporate to achieve } \\
\text { quick social development in a limited amount of } \\
\text { time }\end{array}$ \\
\hline Shilpa Shinde [21] & $\begin{array}{l}\text { It encourages the organizations that provide the } \\
\text { CSR programs in the form of a sustainability } \\
\text { factor } \\
\text { It provides less reputational risks, ready for paying } \\
\text { premium prices, and enhanced customer loyalty } \\
\text { in crisis times }\end{array}$ & $\begin{array}{l}\text { The disciplines do not evolve with the relevant } \\
\text { applications or theoretical contributions }\end{array}$ \\
\hline Saeed Khan [22] & $\begin{array}{l}\text { It provides benefits to the companies those results } \\
\text { in society's positive contribution } \\
\text { It considers particular initiatives for responding to } \\
\text { the local differences }\end{array}$ & The programmers do not consider the root causes \\
\hline Sanclemente-Téllez [23] & $\begin{array}{l}\text { It provides valuable input to the relationship with } \\
\text { the CSR concept } \\
\text { It enhances the organization's financial } \\
\text { performance }\end{array}$ & $\begin{array}{l}\text { It is affected by the altering environment } \\
\text { It cannot be applied to all geographic contexts }\end{array}$ \\
\hline Anjum Amin-Chaudhry [24] & $\begin{array}{l}\text { It provides vast variations in the businesses } \\
\text { conduct } \\
\text { The themes that are identified are reflective }\end{array}$ & $\begin{array}{l}\text { It does not explain the CSR adoption in } \\
\text { governments and corporations }\end{array}$ \\
\hline Sundström and Hjelm-Lidholm [25] & $\begin{array}{l}\text { It extends the customer loyalty } \\
\text { It provides the idea of conviction } \\
\text { It describes the critical constituents as well as their } \\
\text { relations }\end{array}$ & $\begin{array}{l}\text { The customer is not viewed as a human resource } \\
\text { It does not perform the illustration/empirical } \\
\text { testing of the conceptual model } \\
\text { It does not highlight the problems by identifying } \\
\text { the feedback from the customers }\end{array}$ \\
\hline Jaiswal and Gautam [26] & $\begin{array}{l}\text { It eradicates the hunger and poverty } \\
\text { It promotes employment, gender equality, and } \\
\text { education } \\
\text { It ensures health care, women empowerment, } \\
\text { environmental sustainability, sanitation, and } \\
\text { rural development projects }\end{array}$ & $\begin{array}{l}\text { It does not focus on various industries such as } \\
\text { insurance industry, health care industry, IT } \\
\text { industry, and hotel industry, etc } \\
\text { It does not perform the cross country comparison } \\
\text { The empirical study is not performed on different } \\
\text { industries or companies }\end{array}$ \\
\hline Schlegelmilch et al. [27] & $\begin{array}{l}\text { It captures the perceptions and views of the } \\
\text { consumers } \\
\text { The scale acts as a key mediator of consumer } \\
\text { behaviour outcomes and CSR }\end{array}$ & It does not stimulate more in the marketing area \\
\hline
\end{tabular}

lyze the customer's perception regarding the CSR impact on the FMCG companies.

\section{Proposed model of analysing CSR on FMCG industries}

\section{Architectural representation}

The CSR is one among the emerging trend. This technique is relatively new to India in the 2013 company's act, which encouraged the entire companies to involve in the CSR activities. This practice is needed in the trading activities. The concentration is attained a larger extent in handling the FMCG business enterprises. The organization activity arrangement is expedited together with the ethical and soci- etal standards. The CSR is considered as a junction point, in which several necessary activities are considered for ensuring the development and growth of the economy and society and hence the people of the deprived section are uplifted. This architecture analyses the prospective factors that remain as the bottlenecks for customer retention in implementing CSR in Odisha. The analysis undergoes five main categories as below.

- Customer knowledge on CSR activities

- Customer's prospective factors that remain as the bottlenecks for implementing the CSR activities

- Customer's preference to FMCG brands with CSR activities based on company

- Customer's views on impact of CSR on FMCG companies 
- Customer's retention criteria in relation to CSR towards FMCG

The architectural representation of the proposed model of analysing CSR on FMCG industries is displayed in Fig. 1.

These categories consider various factors. The initial category is composed of economic responsibility, ethical responsibility, legal responsibility, and philanthropic responsibility. The second and the third categories are composed of environmental protection, community development, brand loyalty, and quality products with fair price. The fourth category is composed of generate brand awareness and goodwill, and better profit and cost savings. The fifth category is composed of enhanced quality product production owing to the ethical motivation, growth in the market share, and ecofriendly innovative products.

- A questionnaire is prepared in the initial phase for addressing distinct bottlenecks that are associated to the prescribed drivers. The information related to the questionnaire is obtained in the view of Odisha's professional students.

- In the second phase, a questionnaire is distributed to the distinct professional students of Odisha. The entire questions present in the questionnaire are considered as mandatory. Consequently, the industrial authorities are made to choose the exact information as possible.

- In the third phase, a higher-order statistical analysis realizes the behaviour of the drivers. Additionally, the usage of machine learning with the meta-heuristic enhancement is performed for investigating the customer retention in handling the CSR on FMCG industries. Here, M-SLnO on O-RNN is used as the learning algorithm.

\section{Customer knowledge on CSR activities}

This section portrays the customer knowledge on various CSR activities. Several kinds of responsibilities are considered in this section. In Fig. 2a, the CSR is served by environment for $40 \%$ of customers, people for $10 \%$ of customers, communities by $10 \%$ of customers, all by $20 \%$ of customers, and none by $20 \%$ of customers. From Fig. 2b, the complaints from business partners, suppliers, and customers being solved by the CSR is strongly agreed by $30 \%$ of customers, agreed by $30 \%$ of customers, strongly disagreed by $30 \%$ of customers, and disagreed by $10 \%$ of customers. On considering Fig. 2c, the resources offered in CSR in the customer's viewpoint is shown by $30 \%$ for money and volunteers, $20 \%$ for loans, and remaining $10 \%$ for all and others, respectively. From Fig. 2d, the familiar CSR actions in the customer's viewpoint are shown by $40 \%$ for the business foundation, $20 \%$ for the social budget and social partnership, and $10 \%$ for the certification and ethic code. While consider- ing Fig. 2e, the goals achieved by CSR are shown by $30 \%$ for social, $20 \%$ for ecological, all, and none, and $10 \%$ for economic. In Fig. 2f, the CSR practices influencing the image of a company is strongly disagreed by $50 \%$ of the customers, agreed by $30 \%$ of the customers, and strongly agreed by $20 \%$ of the customers. While considering Fig. $2 \mathrm{~g}$, the products purchased from the poor CSR company is described as yes by $20 \%$ of the customers, no by $50 \%$ of the customers, and often by $20 \%$ of the customers. From Fig. $2 \mathrm{~h}$, the CSR playing an important role in the decision-making process is strongly disagreed by $40 \%$ of the customers, agreed by $30 \%$ of the customers, disagreed by $20 \%$ of the customers, and strongly agreed by $10 \%$ of the customers. On considering Fig. 2i, the trust level in the specific products being enhanced by the CSR is strongly disagreed and strongly agreed by $40 \%$ of the customers, and disagreed by $20 \%$ of the customers. From Fig. $2 \mathrm{j}$, the discounts provided by the CSR on the favourite products being attracted is strongly agreed by $50 \%$ of the customers, strongly disagreed and disagreed by $20 \%$ of the customers, and agreed by $10 \%$ of the customers. In Fig. 2k, the money saved by the combo packs of CSR is strongly disagreed by $40 \%$ of the customers, agreed by $30 \%$ of the customers, strongly agreed by $20 \%$ of the customers, and disagreed by $10 \%$ of the customers. On considering Fig. 21, the CSR policies on the regular products is strongly disagreed by $50 \%$ of the customers, strongly agreed by $30 \%$ of the customers, and disagreed by $20 \%$ of the customers. In Fig. 2m, the effectiveness of CSR in solving the feedbacks and customer complaints is disagreed by $40 \%$ of the customers, strongly disagreed by $30 \%$ of the customers, agreed by $20 \%$ of the customers, strongly agreed by $10 \%$ of the customers.

\section{Customer's prospective factors that remain as the bottlenecks for implementing the CSR activities}

Here, the bottlenecks for the prospective factors of the customer for implementing the CSR activities are depicted in Fig. 3. In Fig. 3a, the impatience caused by CSR without providing accurate outcomes is shown as yes by $30 \%$ of the customers, and often by $70 \%$ of the customers. On considering Fig. 3b, the CSR leading to sudden increase in the production cost is revealed as yes and no by $40 \%$ of the customers, and often by $20 \%$ of the customers. In Fig. 3c, the transparency lacking observed in CSR is defined as no by $50 \%$ of the customers, yes by $30 \%$ of the customers, and often by $20 \%$ of the customers. While considering Fig. 3d, the CSR promoting the economic objectives is shown as often by $50 \%$ of the customers, yes by $30 \%$ of the customers, and no by $20 \%$ of the customers. In Fig. 3e, the CSR accomplishing the entire responsibilities is considered as no by $44.4 \%$ of 
Fig. 1 Proposed architecture of analysing the CSR on FMCG industries

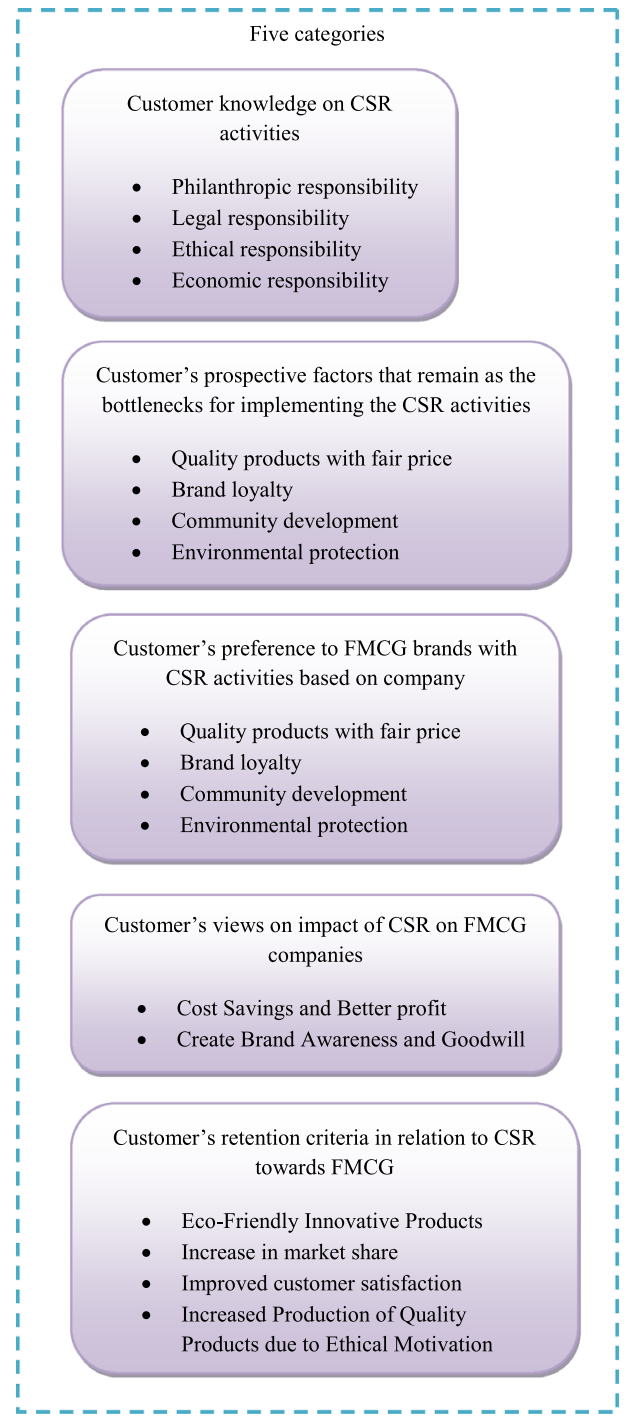

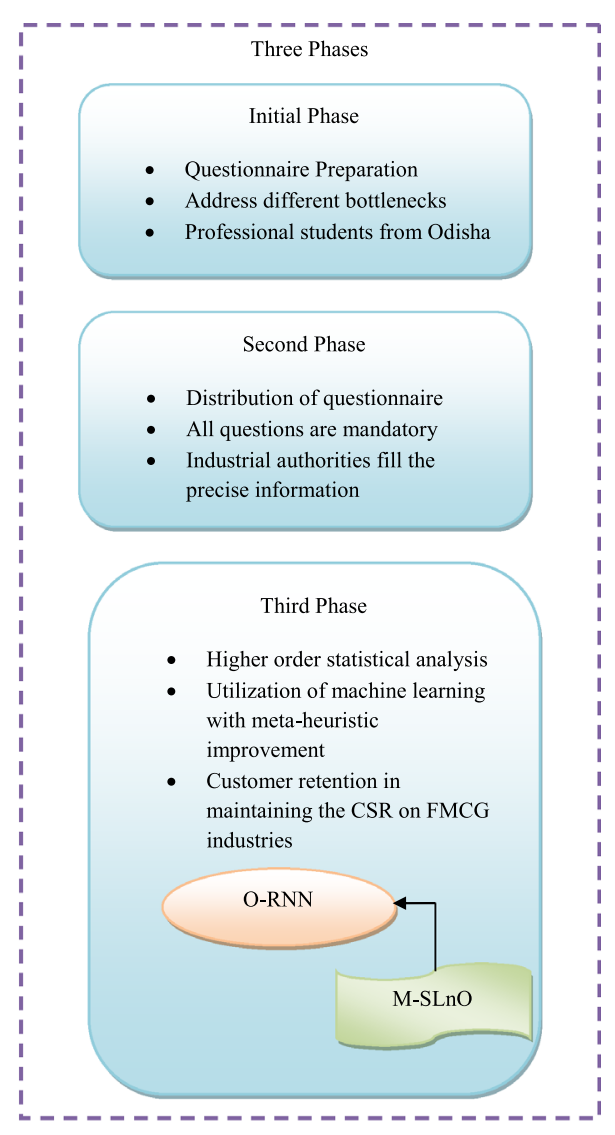

customers, often by $33.3 \%$ of customers, and yes by $22.2 \%$ of customers. From Fig. 3f, the CSR returning low quality products for the highly paid ones are strongly agreed by $40 \%$ of the customers, and agreed, strongly disagreed, and disagreed by $20 \%$ of the customers. In the case of Fig. 3g, the CSR minimizing the cost on small businesses is strongly agreed and disagreed by $40 \%$ of the customers, and agreed and strongly disagreed by $10 \%$ of the customers. On considering Fig. 3h, the CSR conflicting with the profit motive is strongly disagreed by $70 \%$ of the customers, strongly agreed by $20 \%$ of the customers, and disagreed by $10 \%$ of the customers. From Fig. 3i, the CSR offering inappropriate funds is shown as yes by $40 \%$ of the customers, no and often by $30 \%$ of the customers. In Fig. 3j, the CSR transferring the competencies to the individual companies is revealed as yes by $60 \%$ of the customers, no and often by $20 \%$ of the customers. From Fig. 3k, the CSR returning inappropriate responses to the globalization is considered as often by $50 \%$ of the cus- tomers, no by $30 \%$ of the customers, and yes by $20 \%$ of the customers. While considering Fig. 31, the CSR lacking harmonisation is defined as no by $50 \%$ of the customers, yes by $30 \%$ of the customers, and often by $20 \%$ of the customers. In Fig. $3 \mathrm{~m}$, the cost of CSR affecting the selling price is shown as yes by $50 \%$ of the customers, often by $30 \%$ of the customers, and no by $20 \%$ of the customers. On considering Fig. 3n, the CSR lacking empirical evidence is agreed by $50 \%$ of the customers, strongly agreed by $30 \%$ of the customers, strongly disagreed and disagreed by $10 \%$ of the customers. In Fig. 3o, the CSR lacking customer awareness is shown as yes by $50 \%$ of the customers, no by $30 \%$ of the customers, and often by $20 \%$ of the customers. 
Fig. 2 Review of customer knowledge on CSR activities

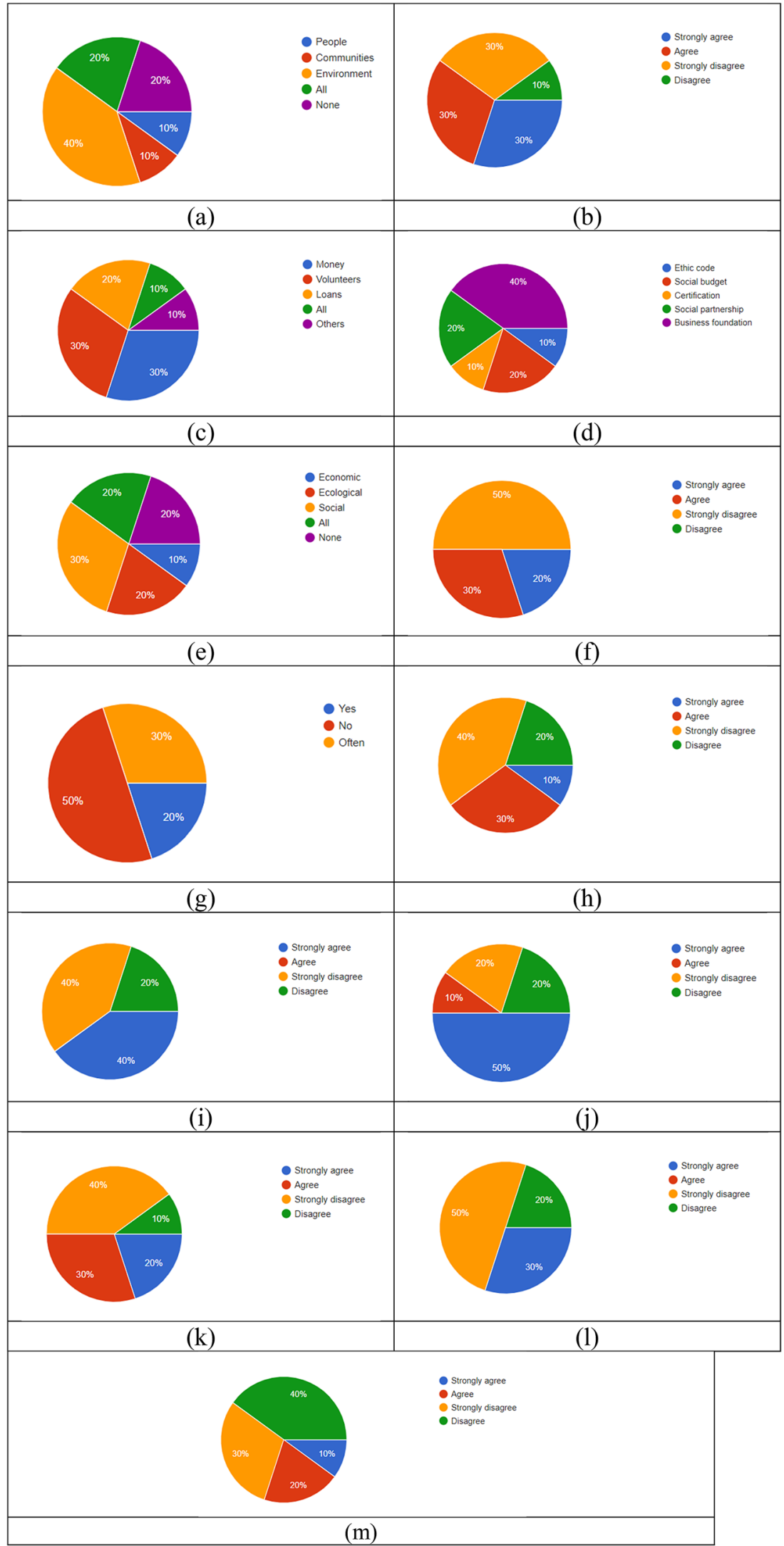


Fig. 3 Prospective factors of the customer that reside as the bottlenecks for implementing the activities of the CSR

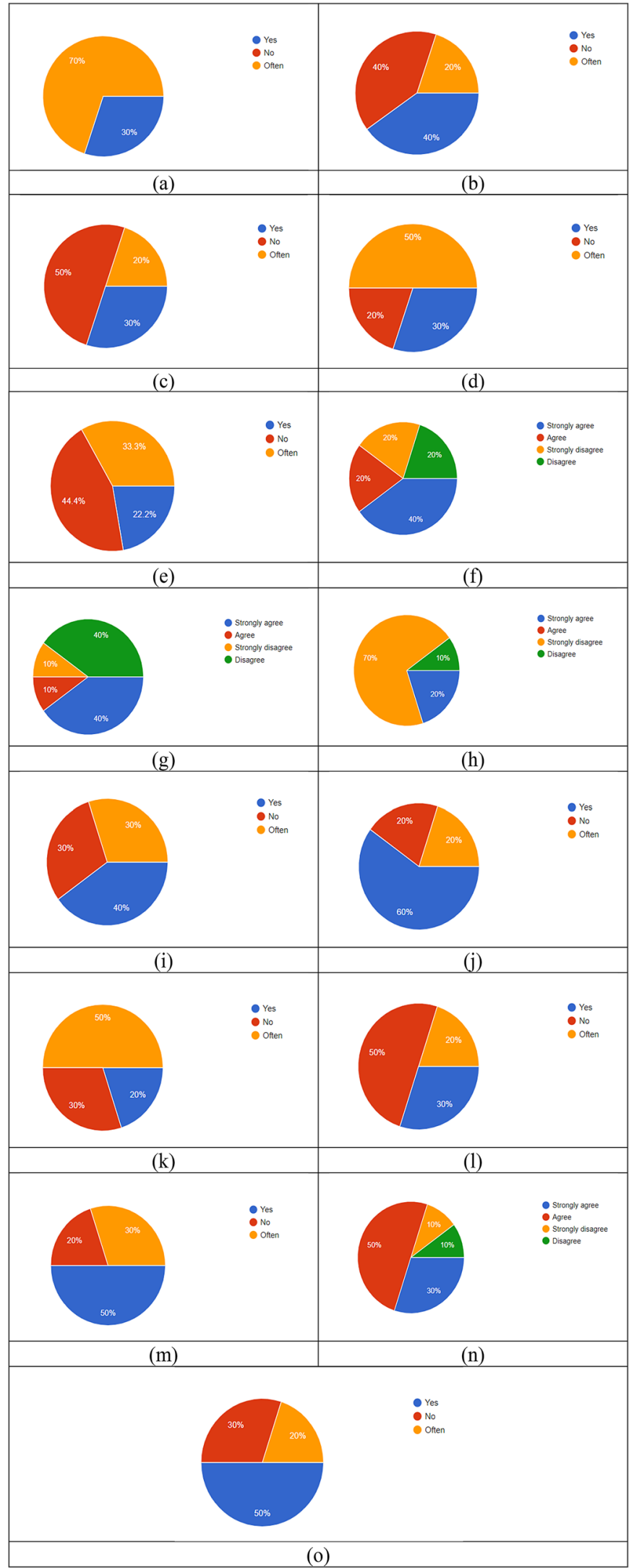




\section{Customer's preference to FMCG brands with CSR activities based on company}

This section explains the preferences of the customer to the FMCG brands with the activities of CSR on the basis of company. In Fig. 4a, the willingness of the customer for paying high price for the favourite FMCG products with CSR is strongly agreed by $50 \%$ of the customers, strongly disagreed by $30 \%$ of the customers, and disagreed by $20 \%$ of the customers. On considering Fig. 4b, the factors inspired by the customer for buying the FMCG products that practices the CSR are shown as $40 \%$ for modern design of products, $20 \%$ for high quality products and others, and $10 \%$ for fewer prices and environmentally friendly products. In Fig. $4 \mathrm{c}$, the factors motivated for frequent purchase of FMCG products with CSR are shown as $30 \%$ for discount, $20 \%$ for service, ambience, and variety, and $10 \%$ for proximity. On considering Fig. 4d, the favourite FMCG brand is of less cost and high quality is agreed by $40 \%$ of the customers, and strongly agreed and strongly disagreed by $30 \%$ of the customers. From Fig. 4e, the duration of using the FMCG brands is given as last 6 months and $1-2$ years by $30 \%$ of the customers, and 6 months to 1 year and more than 2 years by $20 \%$ of the customers. On considering Fig. 4f, the best schemes offered by the FMCG products having CSR is shown as $20 \%$ for coupons, extra quantity, scratch cards, price off, and lucky draws. In Fig. 4g, the switching of regular FMCG to another brand for attaining the promotional scheme is considered as no by $50 \%$ of the customers, yes by $40 \%$ of the customers and often by $10 \%$ of the customers. On considering Fig. 4h, the advertisements motivated for choosing the FMCG brand preference having CSR is selected as news paper by $40 \%$ of the customers, and television, pamphlets, and word of mouth by $20 \%$ of the customers. From Fig. 4i, the extent by which the advertisement generates the need for the FMCG brands having CSR is shown as some extent by $40 \%$ of the customers, never by $30 \%$ of the customers, considerable extent by $20 \%$ of the customers, and never by $10 \%$ of the customers. In the case of Fig. 4j, the favourite FMCG brands of shampoo practicing the CSR is returned as head and shoulders by $40 \%$ of the customers, Sunsilk, and Pantene by $20 \%$ of the customers, and Meera and Clinic plus by $10 \%$ of the customers. While considering Fig. 4k, the favourite FMCG brands of talcum powder practicing the CSR is shown as ponds for $40 \%$ of the customers, Cuticura and Yardley by $20 \%$ of the customers, and Enchanteur and Eva by $10 \%$ of the customers. In Fig. 41, the favourite FMCG brands of toothpaste practicing the CSR are considered as Pepsodent by $40 \%$ of the customers, Himalaya and Colgate by $20 \%$ of the customers, and Sensodyne and Closeup by $10 \%$ of the customers. In the case of Fig. $4 \mathrm{~m}$, the favourite FMCG brands of face cream practicing the CSR are shown as Vicco turmeric by $30 \%$ of the customers, Ponds, Nivea, and Fair and Lovely by
$20 \%$ of the customers, and Loreal by $10 \%$ of the customers. From Fig. 4n, the favourite FMCG brands of bathroom soaps practicing the CSR are returned as Lux by $30 \%$ of the customers, Pears, Rexona, and Dove by $20 \%$ of the customers, and Hamam by $10 \%$ of the customers.

\section{Customer's views on impact of CSR on FMCG companies}

The views of the customer on the impact of the CSR on the FMCG companies are portrayed in Fig. 5. In Fig. 5a, the statement, "customers are no longer price sensitive, they are value sensitive", in terms of CSR on FMCG is agreed by $40 \%$ of the customers, strongly agreed by $30 \%$ of the customers, strongly disagreed by $20 \%$ of the customers, and disagreed by $10 \%$ of the customers. While considering Fig. $5 \mathrm{~b}$, the FMCG registration checking is done or not by the customers before purchasing the objects is returned as often by $50 \%$ of the customers, yes by $30 \%$ of the customers, and no by $20 \%$ of the customers. In Fig. 5c, the opinion regarding the FMCG qualities is considered as showing only for the promotion purpose by $40 \%$ of the customers, true and real by $30 \%$ of the customers, may not be true by $20 \%$ of the customers and other by $10 \%$ of the customers. On considering Fig. 5d, the price of CSR on FMCG is conditions based by $40 \%$ of the customers, economical by $30 \%$ of the customers, all by $20 \%$ of the customers, and high by $10 \%$ of the customers. From Fig. 5e, the motivating factors for buying the FMCG products with CSR is returned as ingredient and durability by $30 \%$ of the customers, goodwill and price by $20 \%$ of the customers. In Fig. 5f, the customer's opinion on whether the brand equity or brand promises of CSR on FMCG companies is chosen as both of these by $40 \%$ of the customers, brand promise by $30 \%$ of the customers, none of these by $20 \%$ of the customers, and brand equity by $10 \%$ of the customers. On considering Fig. 5g, the perspective of the product is dependent on the product origin is given as often by $70 \%$ of the customers, and no by $30 \%$ of the customers. In the case of Fig. 5h, the internet shopping adaptability with FMCG companies having CSR is strongly disagreed by $40 \%$ of the customers, and strongly agreed, agreed, and disagreed by $20 \%$ of the customers. While considering Fig. 5i, the convincing of the customers by the FMCG companies through selling other brand than their needs is returned as yes by $60 \%$ of the customers, no and often by $20 \%$ of the customers. In the case of Fig. 5j, the satisfaction of the current features of the FMCG products with CSR is recommended as not very satisfied by $40 \%$ of the customers, extremely satisfied and dissatisfied by $20 \%$ of the customers, and very satisfied and moderately satisfied by $10 \%$ of the customers. On considering Fig. 5k, the choice of purchasing the services/products of the FMCG companies practicing CSR is given as yes and 
Fig. 4 Preferences of the customer to FMCG brands with CSR activities based on company

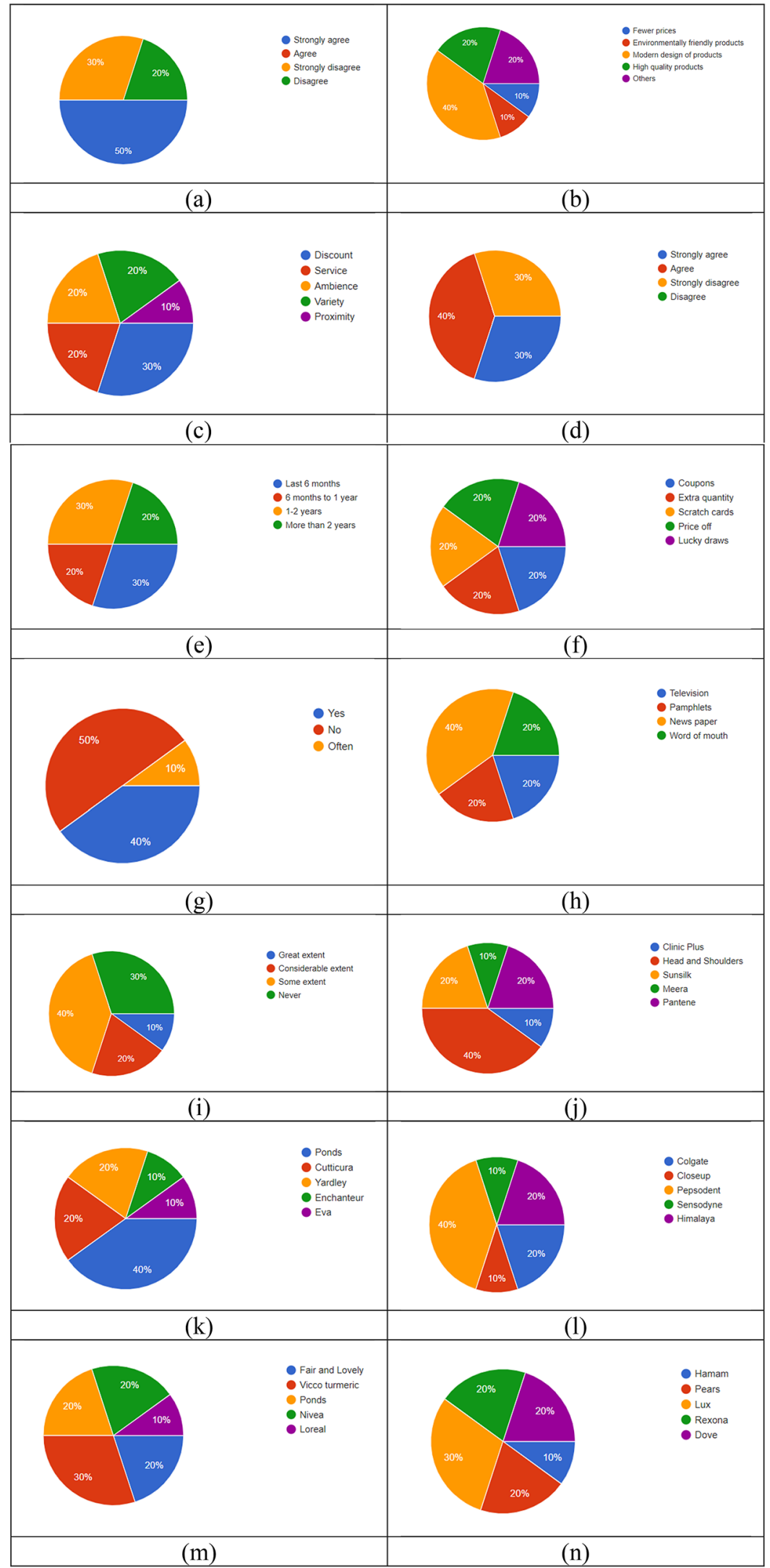


Fig. 5 Reviews of the customer on impact of CSR on FMCG companies

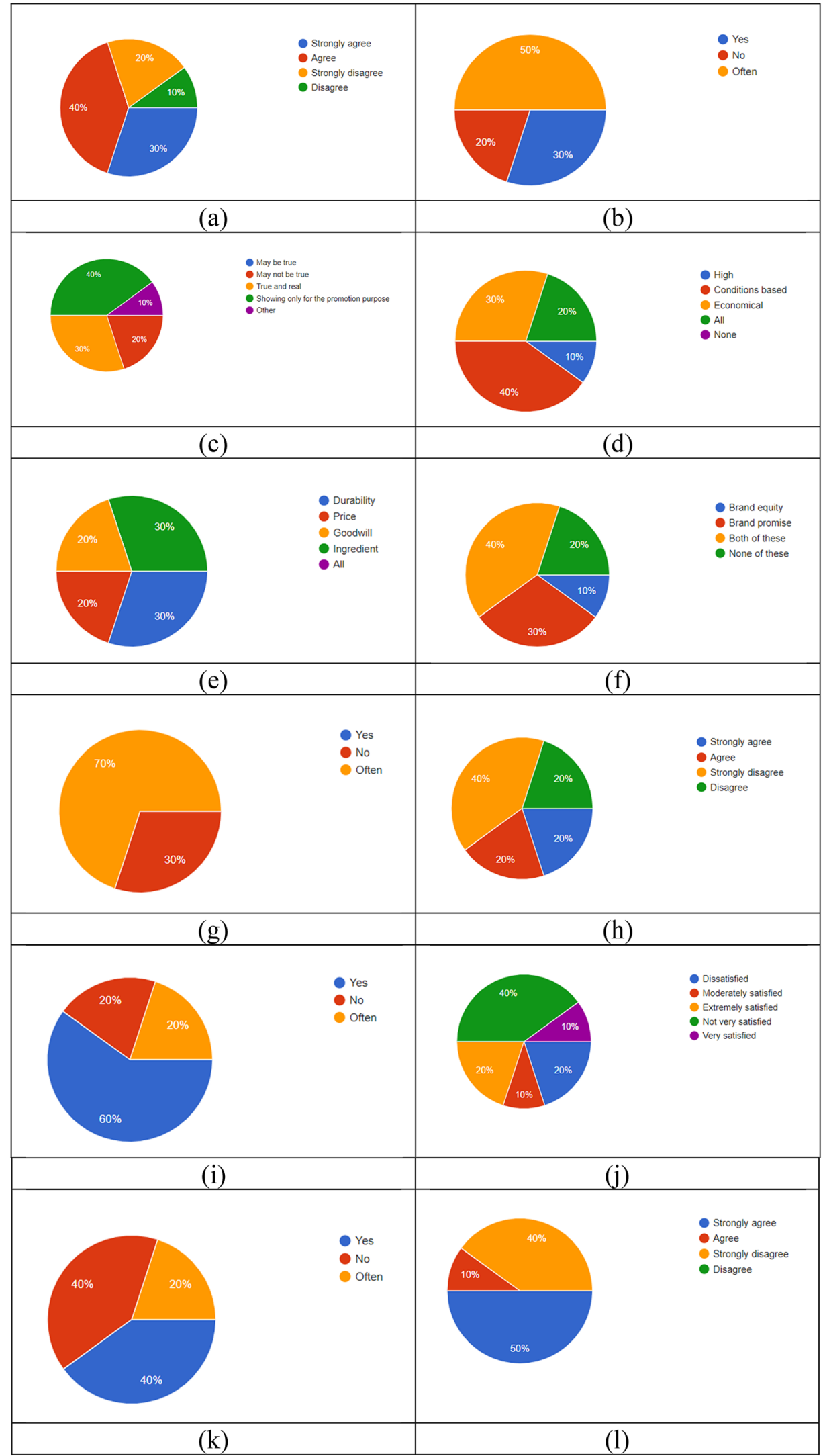


no by $40 \%$ of the customers, and often by $20 \%$ of the customers. From Fig. 51, the satisfaction of the features provided by the FMCG companies on CSR on the specific products is strongly agreed by $50 \%$ of the customers, strongly disagreed by $40 \%$ of the customers, and agreed by $10 \%$ of the customers.

\section{Customer's retention criteria in relation to CSR towards FMCG}

The retention criteria of the customer in relation with the CSR towards FMCG are displayed in Fig. 6. In Fig. 6a, the opinion regarding the great service given by the FMCG companies practising CSR tempts to buy regularly its brands is returned as yes by $50 \%$ of the customers, often by $40 \%$ of the customers, and no by $10 \%$ of the customers. On considering Fig. $6 \mathrm{~b}$, the issues being solved by the FMCG companies with CSR for attaining the consumer retention is considered as often by $60 \%$ of the customers, and yes by $40 \%$ of the customers. In Fig. $6 \mathrm{c}$, the fact that the quality provided by the FMCG companies with CSR retaining the customers is strongly agreed and strongly disagreed by $40 \%$ of the customers, and agreed by $20 \%$ of the customers. While considering Fig. 6d, the product improvement by the FMCG companies on the basis of the customer feedback retaining the customer to it is recommended as yes and no by $40 \%$ of the customers, and often by $20 \%$ of the customers. In Fig. 6e, the FMCG companies with CSR focusing on the complete experience for the favourite brand for retaining the customer to it is suggested as yes by $40 \%$ of the customers, and no and often by $30 \%$ of the customers. From Fig. 6f, the payment in a simple mode retaining the customer to a specific brand of FMCG having CSR is returned as yes by $50 \%$ of the customers, often by $30 \%$ of the customers, and no by $20 \%$ of the customers. In the case of Fig. $6 \mathrm{~g}$, the fact that the accurate online services offered by the FMCG companies practising CSR retain the customer's favourite brand is given as strongly disagree by $70 \%$ of the customers, and strongly agree by $30 \%$ of the customers. On considering Fig. 6h, the frequent listening of consumer needs by the FMCG brands makes the customer to retain their favourite brand is strongly agreed by $70 \%$ of the customers, strongly disagreed by $20 \%$ of the customers, and agreed by $10 \%$ of the customers. In Fig. 6i, the lower cost on the favourite brands by the FMCG brands having CSR makes the customer retain that specific band is suggested as no by $50 \%$ of the customers, often by $30 \%$ of the customers, and yes by $20 \%$ of the customers. From Fig. 6j, the complaints of the customer are fulfilled without any conflicts for retaining the favourite FMCG brand by the customer practising CSR is recommended as no by $40 \%$ of the customers, and yes and often by $30 \%$ of the customers.

\section{Deep learning impact on CSR activities}

\section{Deep learning for CSR activities}

Here, five categories are considered for investigating the customer retention in handling the CSR on FMCG industries. Each category consists of more than ten questions. The RNN network is assigned for each category, hence a total of five RNN networks are assigned. Each question has responses that are modelled in the form of multiple responses. The responses are collected from the professional students of Odisha. The responses vary according to each customer's preference. From the gathered responses, the score is assigned for each response. The possibilities related to the score of every response are described. These possibilities are given to the optimized RNN for predicting the future responses. In the optimized RNN, the training, as well as the testing process, takes place. During the process of training, the possibilities are given as input to the optimized RNN and the target fixed is the mean (scores). In the testing process, the same possibilities are given as input to the optimized RNN and the output attained is the predicted (score) that is related to the future responses. Here, the hidden neurons of the RNN are optimized using the proposed M-SLnO, hence it is called as optimized RNN. This optimized RNN predicts the overall response that is considered as the predicted response as the output. The architectural representation of the deep learning impact on CSR activities is shown in Fig. 7. It helps to have a clear analysis on diverse CSR activities.

\section{Optimized RNN}

The RNN is used as the learning algorithm for investigating the customer retention in handling the CSR on FMCG industries. RNN [30] is a group of Artificial Neural Network (ANN). The directed graph is formed by the connections among the nodes. The temporal behaviour is modelled for a time sequence. The output is based on the earlier computations. The relationship is characterized among the current and the earlier output for handling the sequential progression. The high-level correlation is described clearly. In the previous era, the performance of the RNN was lessened because of the complexities happening during the process of training. The unsolved problems are the explosion as well as the gradient mass and it leads to the emergence of the special form of RNN called Long Short Term Memory (LSTM). LSTM involves, "memory cell unit, forget gate, input gate, and output gate". The unnecessary information is discarded and only the useful information is considered. Another special kind of LSTM is the Gate Recurrent Unit (GRU). The RNN is made simple by the GRU without affecting the performance. Hence, RNN is constructed by the GRU. The forget and output gates are joined by the GRU into a single update 


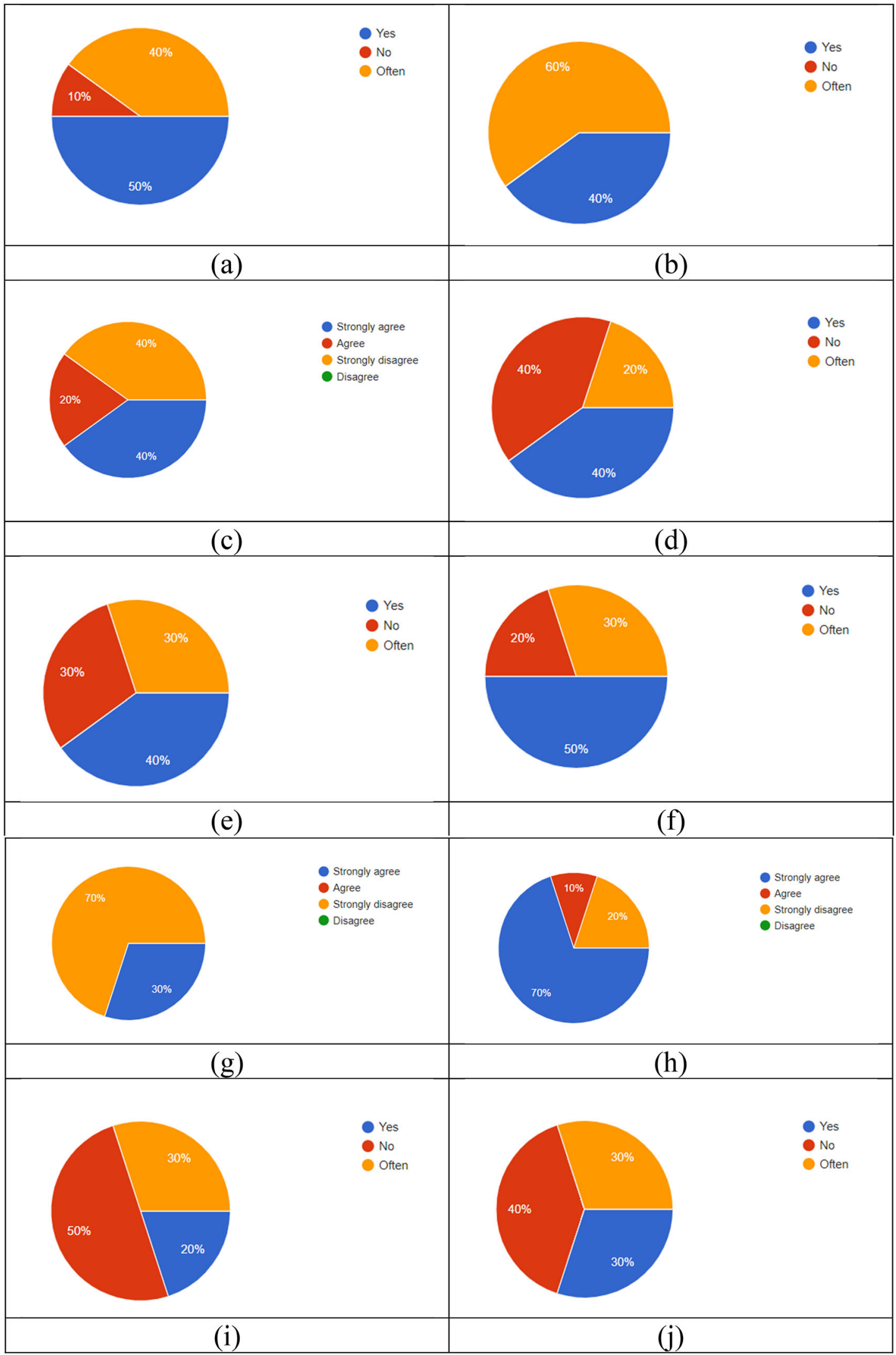

Fig. 6 Retention criteria of the customer in relation to the CSR towards FMCG 


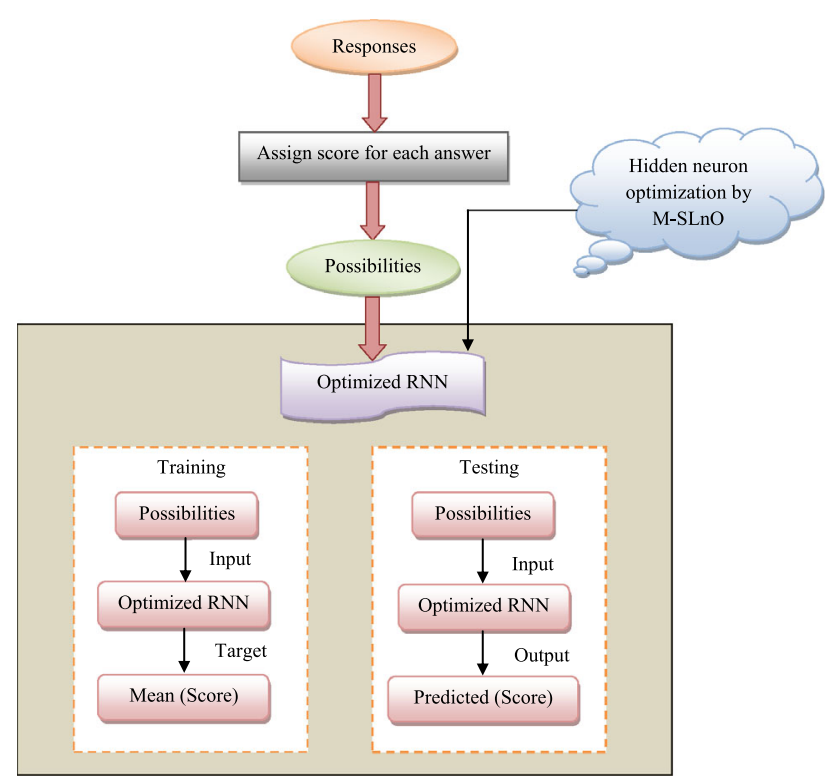

Fig. 7 Architectural representation of the deep learning impact on CSR activities

gate $z i$. The current state is attained by the output gate with the help of linear interpolation. It also provides easier training and lesser parameters. When the input is considered as $\left(x i_{i i}, h i_{i i-1}\right)$, which describes the input features of the $i i^{t h}$ slice and the earlier hidden state, the reset gate $r i$ and the update gate $z i$ are measured as in Eq. (1) and Eq. (2).

$$
\begin{aligned}
& z i_{i i}=\sigma\left(W I^{x i z i} x i_{i i}+W I^{h i z i} h i_{i i-1}\right) \\
& r i_{i i}=\sigma\left(W I^{x i r i} x i_{i i}+W I^{h i r i} h i_{i i-1}\right)
\end{aligned}
$$

In the above equations, the corresponding matrices are given by $W I^{x i z i}, W I^{h i z i}, W I^{x i r i}$, and $W I^{\text {hiri }}$, and a logistic sigmoid function is given by $\sigma$, respectively. The candidate state related to the hidden unit is given by Eq. (3).

$h \tilde{i}_{i i}=\tan \left(W I^{x i h i} x i_{i i}+W I^{h i h i}\left(h i_{i i-1} \Theta r i_{i i}\right)\right)$

Here, the element wise multiplication is given by $\Theta$. The $i i^{\text {th }}$ hidden activation state $h i_{i i}$ of GRU defines a linear interpolation among the candidate state $h \tilde{i}_{i i}$ and previous state $h i_{i i-1}$ as in Eq. (4).

$$
\begin{aligned}
h i_{i i}= & \left(1-z i_{i i}\right) \Theta h \tilde{i}_{i i}+z i_{i i} \Theta h i_{i i-1} h i_{i i}=\left(1-z i_{i i}\right) \Theta h \tilde{i}_{i i} \\
& +z i_{i i} \Theta h i_{i i-1}
\end{aligned}
$$

The traditional RNN offers several benefits such as it models a group of records, every pattern is based on the previous groups, expands the powerful pixel neighbourhood, very precise in the prediction process, etc. Yet, it lacks from slow

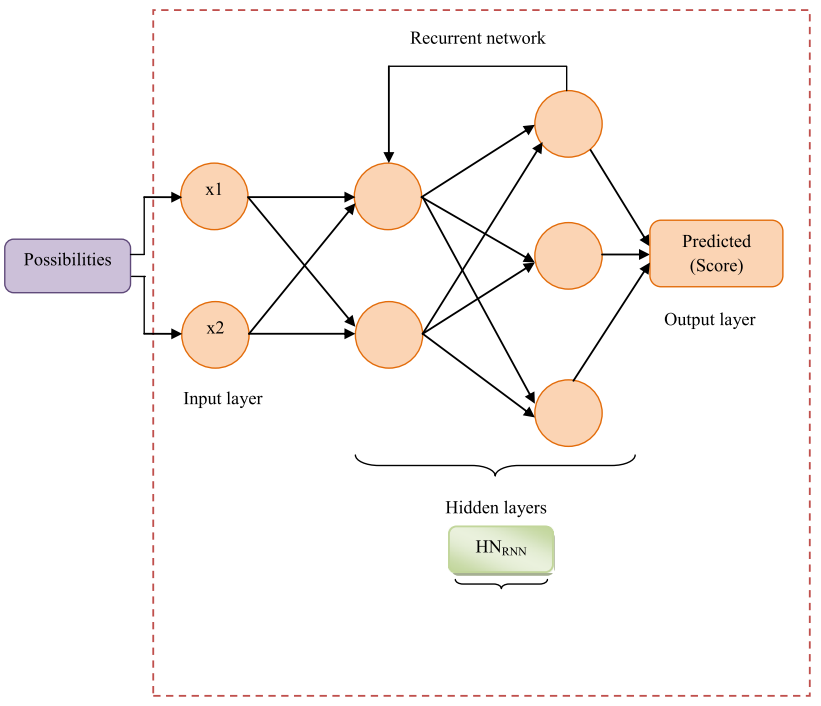

Fig. 8 Optimized RNN for prediction

computation, difficult training process, complexity in processing the lengthy sequences, suffers from issues such as gradient vanishing or exploding. Therefore, these drawbacks are handled by optimizing the hidden neurons of the RNN using the M-SLnO with the consideration of minimizing the RMSE. This O-RNN offers better speed, efficiency, enhances the exploitation of global as well as the local information present in a sequence, captures both the past as well as the future context of the input sequence, etc.

The major objective of the O-RNN-based CSR on consumer retention for FMCG industries is to minimize the RMSE by optimizing its hidden neurons. The bounding limit of the hidden neurons lies in between 5 and 255 . Hence, the major objective is designed as in Eq. (5).

Fit $=\underset{\left\{H N_{R N N}\right\}}{\arg \min }(R M S E)$

Here, the objective is defined by Fit, and the hidden neurons of O-RNN are defined by $H N_{R N N}$, respectively. The RMSE is defined as, "it is a frequently used measure of the differences between values predicted by a model or an estimator and the values observed" as in Eq. (6).

$\mathrm{RMSE}=\sqrt{\frac{\sum_{e i c=1}^{n j c}\left(f o c_{e i c 2}-a c c_{e i c 1}\right)^{2}}{n j c}}$

In the above equation, the computation value for every fitted point is shown by eic, the actual value is shown by $a c c$, the fitted point count is shown by $n j c$, and the predicted value is shown by $f o c$, respectively. The diagrammatic representation of the optimized RNN is shown in Fig. 8. 


\section{Proposed M-SLnO}

The proposed M-SLnO for investigating the customer retention in handling the CSR on FMCG industries is used to optimize the hidden neurons of the O-RNN for minimizing the error between the actual and the predicted outcome. SLnO [31] criticizes the sea lion hunting behaviour. It is motivated by the whisker of the sea lion for detecting the prey. The significant phases of the sea lion's hunting characteristics are as follows: "tracking as well as chasing the prey; pursuing and encircling the prey, and attack towards the prey". The target prey is assumed as the nearby optimal solution or the current best solution in the detecting and tracking phase as given in the following equation:

Dist $\vec{p}=|2 B \vec{P} \cdot P P(t \vec{p})-S L P(t \vec{p})|$.

In the above equation, the position vector of the sea lion is defined by $\operatorname{SLP}(t \vec{p})$, the position vector of the target prey is defined by $P P(t \vec{p})$, the distance among the sea lion and target prey is defined by $\operatorname{Dist} \vec{p}$, the random vector in [0,1] is defined by $B \vec{P}$, and the current iteration is defined by $t p$. In the next iteration, the sea lions move to the target prey as in the following equation:

$S L P(t p+\overrightarrow{1})=P P(t \vec{p})-\operatorname{Dist} \vec{p} \cdot C \vec{P}$.

Here, the term $C \vec{P}$ decreases linearly over the iterations, and the next iteration is defined by $(t p+1)$. The identified prey is encircled and attacked by other members in the vocalization phase as in the following equations:

$S P \vec{P}_{\text {leader }}=\left|\left(V \vec{P}_{1}\left(1+V \vec{P}_{2}\right)\right) / V \vec{P}_{2}\right|$,

$V \vec{P}_{1}=\sin \theta$

$V \vec{P}_{2}=\sin \varphi$.

In the above equations, the speed of sounds in water as well as the air is defined by $V \vec{P}_{1}$ and $V \vec{P}_{2}$, and the speed of sound of sea lion leader is shown by $S P \vec{P}_{\text {leader }}$, respectively. In the attacking (exploitation) phase, the sea lions identify the target prey position and encircle them. Here, the dwindling encircling technique is based on the $C \vec{P}$ value. In the case of circle updating position, the bait ball of fishes is chased by the sea lions as in the following equation:

$$
\begin{aligned}
S L \vec{P}(t p+1)= & |P \vec{P}(t p)-S L \vec{P}(t p)| \\
& \cdot \cos (2 \pi m p)+P \vec{P}(t p) .
\end{aligned}
$$

Here, the absolute value is defined by $\|$, the distance among the sea lion (search agent) and the target prey (best optimal position) is defined by $|P \vec{P}(t p)-S L \vec{P}(t p)|$, and a random number is defined by $m p$, respectively. In the exploration phase (searching for prey), this algorithm accomplishes a global search agent and the global optimal solution is found as in the following equations:

$\operatorname{Dist} \vec{p}=\left|2 B \vec{P} \cdot S \vec{L}_{r n d p}(t p)-S L P(t \vec{p})\right|$,

$S L \vec{P}(t p+1)=S L \vec{P}_{r n d p}(t p)-\operatorname{Dist} \vec{p} \cdot C \vec{P}$.

In the above equation, a random sea lion from the present population is defined by $S L \vec{P}_{r n d p}(t p)$, respectively.

The traditional SLnO offers several benefits such as competitive than other metaheuristic algorithms, better exploitation phase, exploration phase, and good convergence behaviour. But, it limits from certain facts such as consuming more time, fails in handling the multi-objective problems, etc. Hence, the algorithm is designed using the nearest solution in the exploration phase instead of the random solution on the basis of the distance, therefore, called as M-SLnO. This M-SLnO consumes less time, returns accurate optimal outcomes, and cal also handles all kinds of multi-objective optimization problems, etc.

In the traditional $\mathrm{SLnO}$, if $(|C P| \geq 1)$, then the solution update is done by the current search agent location as in Eq. (14). But, in the proposed M-SLnO, if $(|C P| \geq 1)$, instead of random solution in the exploration phase, the nearest solution is used on the basis of the distance as in the following equation:

$\operatorname{distp}=\sum_{i p=1}^{N P o P}\left\|S L \vec{P}(t p)-S P \vec{P}_{\text {leader }}\right\|$.

The minimum index of distances is found as in the following equation:

Dist $\vec{p}=\left|2 B \vec{P} \cdot S \vec{L}_{\text {near }}(t p)-S L P(t \vec{p})\right|$.

Here, the term $S \underset{\text { near }}{\vec{L}}$ represents the nearest solution on the basis of the distance. Hence the solution update in the 
exploration phase of M-SLnO is done using the new updated formula as in the following equation:

$S L \vec{P}(t p+1)=S L \underset{n e a r}{\vec{P}}(t p)-\operatorname{Dist} \vec{p} \cdot C \vec{P}$

In the above equation, the distance Dist $\vec{p}$ is computed using Eq. (10). The pseudo code of the proposed M-SLnO is shown in Algorithm 1 and the flowchart of the proposed M-SLnO is shown in Fig. 9.

\section{Results and discussion}

\section{Experimental setup}

The proposed M-SLnO-RNN-based CSR on customer retention for FMCG industries was implemented in MATLAB 2020a and the results were carried out. Here, the dataset was considered as the response given by the professional students of Odisha on the five categories. The population size was considered as 10 and the total iterations performed were 25 . Here, the prediction analysis of the optimized RNN was compared with several existing deep learning algorithms such as KNN [28], SVM [29], NN [18], and RNN [30] with consideration

\begin{tabular}{|l|}
\hline \multicolumn{1}{|c|}{ Algorithm 1: Pseudo code of proposed M-SLnO } \\
\hline Begin \\
Population initialization \\
Choose $S T L \vec{P}_{\text {rand }}$ \\
Compute fitness function for every search agent \\
The best candidate search agent is the $S L \vec{P}$ having best fitness \\
While ( $t p<$ maximum iteration count) \\
Compute $S P \vec{P}_{\text {leader }}$ by Eq. (9) \\
If $\left(S P \vec{P}_{\text {leader }}<0.25\right)$ \\
If $(|C P|<1)$ \\
$\quad$ Best search agent location update as in Eq. (7) \\
$\quad$ Else \\
$\quad$ A nearby search agent $\left(S L \vec{P}_{\text {near }}\right)$ is used on the basis of the distance \\
$\quad$ as in Eq. (15). \\
$\quad$ Compute the distance using Eq. (16) \\
$\quad$ Solution update in the exploration phase using the newly \\
$\quad$ modified nearest solution as in Eq. (17). \\
Else \\
Current search agent location update as in Eq. (12) \\
Fitness function computation for every search agent \\
If better solution exists, update $S L \vec{P}$ \\
Best solution is returned as $S L \vec{P}$ \\
End \\
Stop
\end{tabular}

The modified optimization algorithms offers several benefits such as efficiency in solving the problems for finding the appropriate mathematical models, less computational time, does not overlap, converges faster, high efficiency and probability in attaining the global optima, is robust, etc. [32]. It also has the ability to run in parallel computation and is composed of only few parameters to adjust, etc. [33]. of several error measures such as, "MEP, SMAPE, MASE, MAE, RMSE, L1 Norm, L2 Norm, and L-Infinity Norm" and the statistical analysis was also done for the five categories, respectively. 


\section{Error measures}

Here eight error measures are considered and they are described below.

(a) L-Infinity Norm: "The length of a vector can be calculated using the maximum norm".

$L C_{\text {inf }}=\max _{1 \leq e i c \leq n j c}\left|L C_{e i c}\right|$

(b) SMAPE: "SMAPE is an accuracy measure based on percentage errors".

$\mathrm{SMAPE}=\frac{100 \%}{n j c} \sum_{e i c=1}^{n j c} \frac{|f o c-a c c|}{\frac{(|a c c|+|f o c|)}{2}}$

(c) RMSE: It is clearly described in Eq. (6).

(d) L2 Norm: "It is the shortest distance to go from one point to another". It is also taken as Euclidean norm.

$L C 2=\left(\sum_{e i c=1}^{n j c} L C_{e i c}^{2}\right)^{\frac{1}{2}}$

(e) MEP: "the MEP is the computed average of percentage errors by which forecasts of a model differ from actual values of the quantity being forecast".

$\mathrm{MEP}=\frac{100 \%}{n j c} \sum_{e i c=1}^{n j c} \frac{a c c-f o c}{a c c}$

(f) MAE: "It is a measure of difference between two continuous variables".

MAE $=\frac{\sum_{e i c=1}^{n j c}\left|f o c_{e i c}-a c c_{e i c}\right|}{n j c}$

(g) L1 Norm: "L1 Norm is the sum of the magnitudes of the vectors in a space".

$L C_{1}=\sum_{e i c}\left|L C_{e i c}\right|$

Here, $L C$ is a matrix, and $e i c=1,2, \cdots, E i c$, and Eic is the size of the matrix.

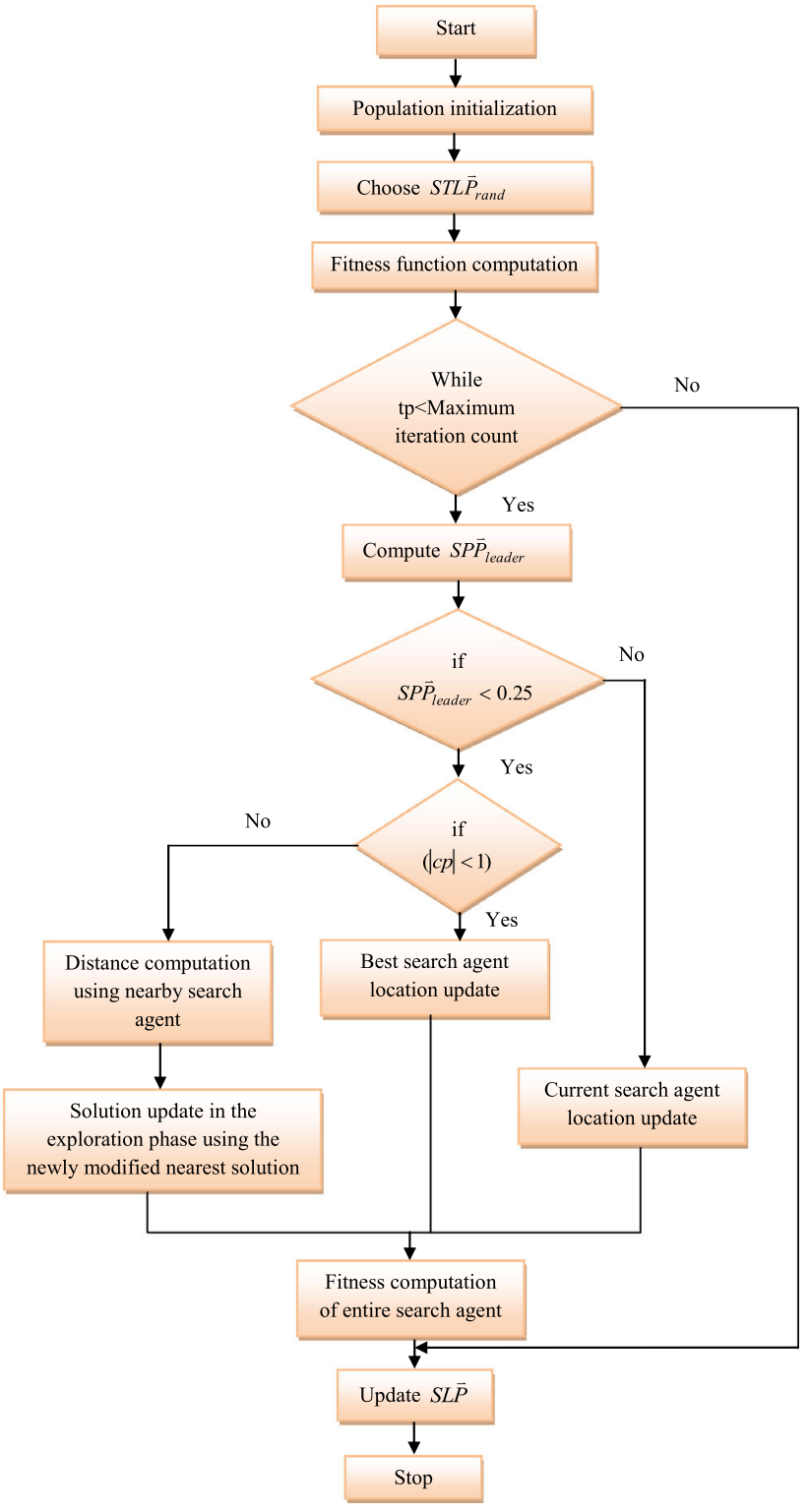

Fig. 9 Flowchart of the proposed M-SLnO

(h) MASE: "It is the mean absolute error of the forecast values, divided by the mean absolute error of the insample one-step naive forecast".

$\operatorname{MASE}=\operatorname{mean}\left(\frac{|f o c|}{\frac{1}{n j c-1} \sum_{e i c=1}^{n j c}\left|a c c_{e i c}-a c c_{e i c-1}\right|}\right)$

\section{O-RNN prediction analysis}

The prediction analysis of the RNN in the case of proposed ORNN and the existing deep learning models CSR on customer retention for FMCG industries is clearly shown in Fig. 10. 
Fig. 10 Prediction analysis of O-RNN against conventional machine learning models in terms of various error measures such as, "a MEP, b SMAPE, c MASE, d MAE, e RMSE, f L1 Norm, $g$ L2 Norm, and h L-Infinity Norm"

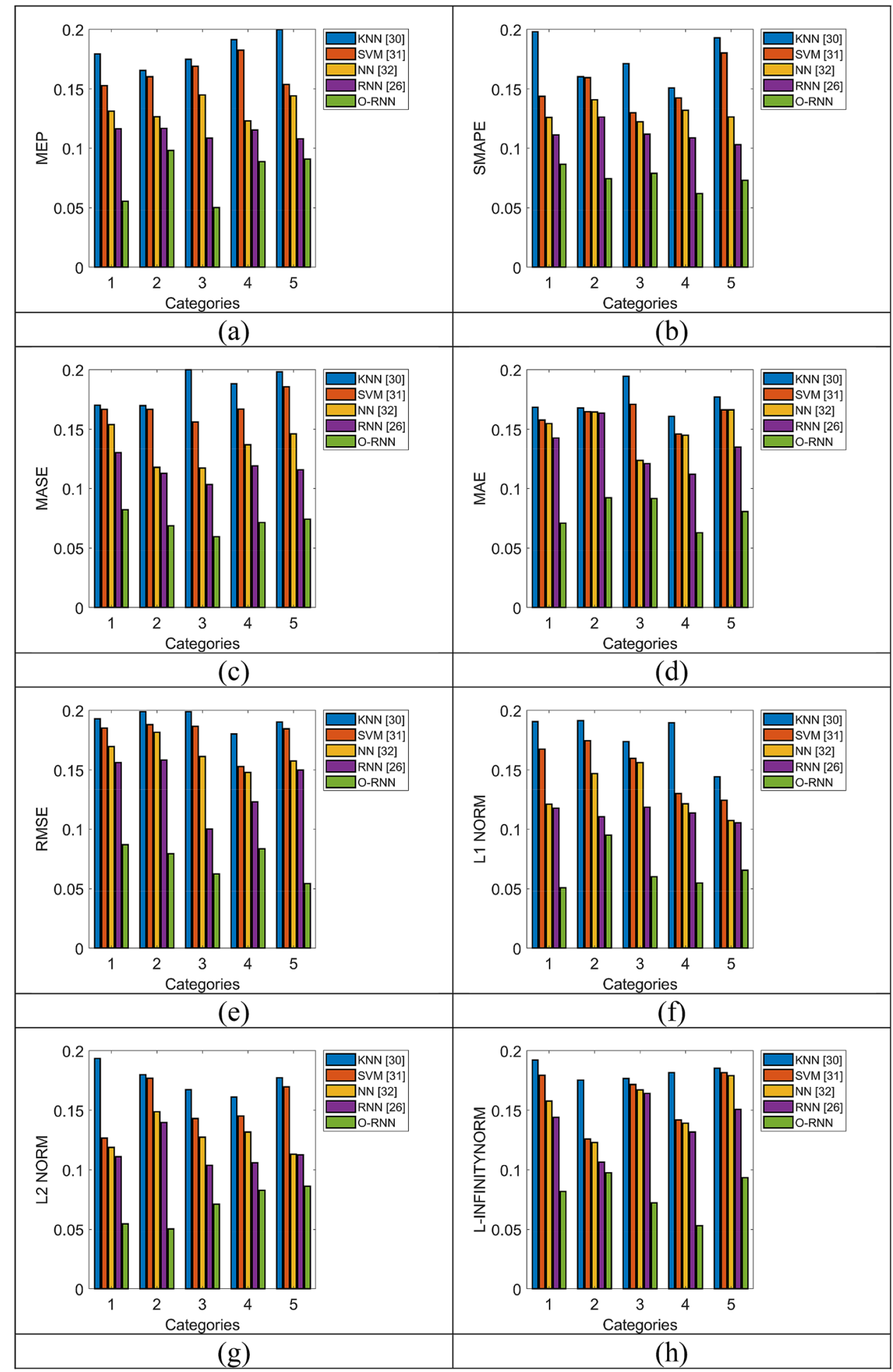

Here, the response is attained for all the five defined categories. Each response is converted to the score. The converted score is predicted using the RNN. The output, considered as the overall response is obtained for each response. Here, in Fig. 10a, for category 4, the MEP of the proposed O-RNN for the overall response is $33.33 \%, 38.46 \%, 2.86 \%$, and $52.94 \%$ improved than RNN, NN, SVM, and KNN, respectively. Hence, the proposed O-RNN predicts the overall response of the customer on CSR for FMCG industries more superior than the other existing deep learning models. 
Fig. 11 Statistical analysis for analysing the effect of CSR on consumer retention for FMCG industries, "a category 1 , b category 2, c category 3 , d category 4 , and e category 5 "

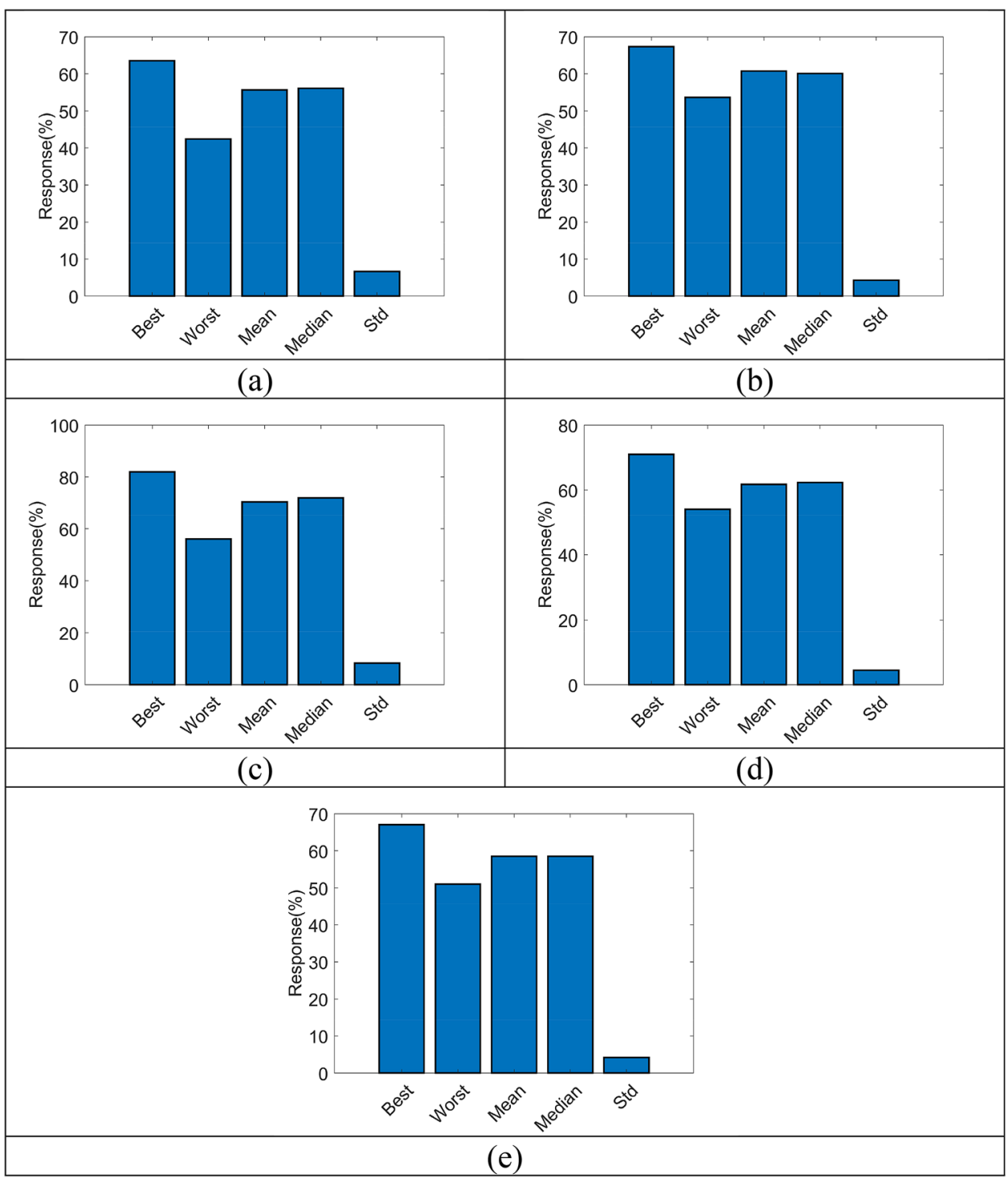

\section{Statistical analysis}

For category 1, 10 overall response is achieved from which the statistical analysis is performed. From the entire responses, the percentage of scores of statistical analysis in terms of best (positive), worst (negative), mean, median, and standard deviation is attained. The statistical analysis of all the five categories is clearly shown in Fig. 11. In Fig. 11a, for customer knowledge on CSR activities, 64\% of response is positive, $42 \%$ of response negative, and $55 \%$ of people have customer knowledge on CSR activities. Hence, the proposed O-RNN predicts the overall response of the customer on CSR for FMCG industries more superior than the other existing deep learning models.

\section{Comparison of the proposed 0-RNN with existing models}

The comparison of the proposed O-RNN with existing models on consumer retention for FMCG industries is shown in Fig. 12. In Fig. 12a, the MEP of the proposed O-RNN performs $16.67 \%$, and $28.57 \%$ better than the AHP and CF at category 2 . Hence, the proposed O-RNN predicts the overall response of the customer on CSR for FMCG industries more superior than the other existing deep learning models.

\section{Discussion}

The proposed O-RNN is useful for the time series prediction. It has high speed convergence particularly in the largescale global optimization. Because of these advantages, this method performs better than the other existing methods. The 
Fig. 12 Comparison of the proposed O-RNN with existing models on consumer retention for FMCG industries in terms of "a MEP, b SMAPE, c MASE, d MAE, e 2 Norm, and f L-Infinity Norm"

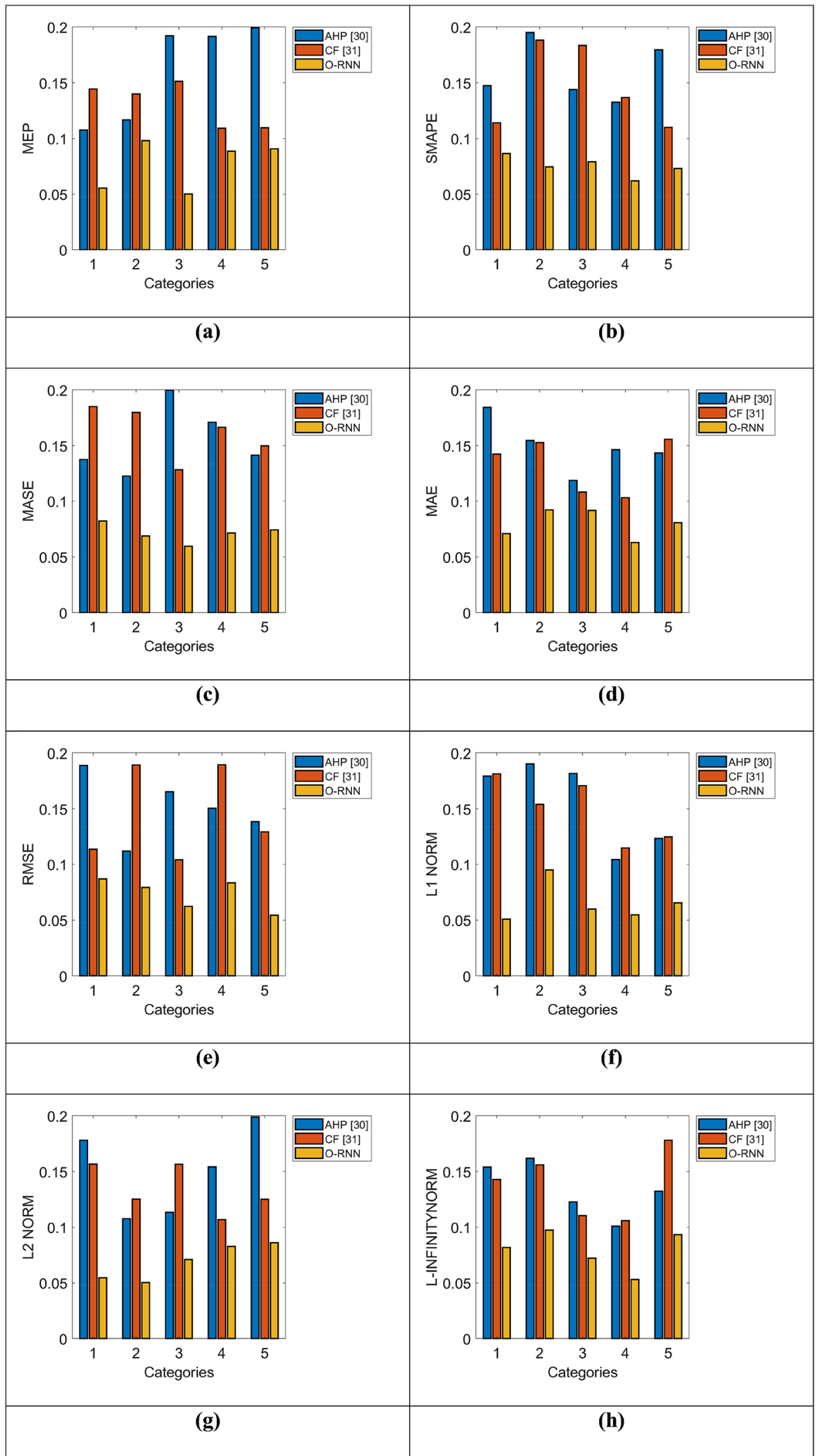


proposed O-RNN has been applied in several applications like speech recognition, video tagging, and prediction problems. In this paper, the CSR activities have been analyzed on the FMCG industries which are based on the retention of the FMCG products. The main objective of the paper is to minimize the RMSE on consumer retention for FMCG industries by optimizing its hidden neurons. It is verified by the generated results on benchmark datasets, where the efficiency of the proposed model in terms of accuracy is consistently achieved higher for all the datasets by all the algorithms, but the proposed O-RNN gets better values than other algorithms. The optimized RNN was compared with the existing deep learning algorithms such as KNN, SVM, $\mathrm{NN}$, and RNN with consideration of several error measures such as, "MEP, SMAPE, MASE, MAE, RMSE, L1 Norm, L2 Norm, and L-Infinity Norm. Some of the generated results are validated here for discussing the efficiency of the suggested model. On considering Fig. 10d, for category 2, the MAE of the proposed O-RNN for the overall response is $53.85 \%, 60 \%, 64.71 \%$, and $66.67 \%$ better than RNN, NN, SVM, and KNN, respectively. Moreover, from Fig. 10e, for category 5, the RMSE of the proposed O-RNN for the overall response is $25 \%, 30.77 \%, 43.75 \%$, and $47.06 \%$ higher than RNN, NN, SVM, and KNN, respectively. The existing methods NN, SVM, and KNN have performed lower because of the disadvantages in its performances. The duration of the $\mathrm{NN}$ is unknown and it requires more data than the others. The SVM takes more time for training for the large datasets. The KNN does not have the training period. Thus, the suggested model takes more advantages than others. On considering Fig. $11 \mathrm{~b}$, customer's prospective factors that remain as the bottlenecks for implementing the CSR activities, $68 \%$ of the response is positive, $53 \%$ of the response negative, and $60 \%$ of the response telling the customer's prospective factors that remain as the bottlenecks for implementing the CSR activities. From Fig. 11c, customer's preference to FMCG brands with CSR activities based on company, $82 \%$ of the response is positive, $57 \%$ of the response is negative, and $70 \%$ of the response is showing the customer's preference to FMCG brands with CSR activities. From Fig. 11d, customer's views on impact of CSR on FMCG companies, 70\% of the response is positive, and $54 \%$ of response is negative. Further, in Fig. 11e, customer's retention criteria in relation to CSR towards FMCG, $67 \%$ of the response is positive, and $50 \%$ of the response is negative. Hence, the experimental analysis on proposed heart disease prediction model establishes the better performance than conventional clustering approaches in terms of different performance measures.

\section{Conclusions}

This paper has investigated the impact of CSR activities on the FMCG based on the customer retention of FMCG products. A questionnaire was prepared initially that was composed of five categories. The information regarding the questionnaire was attained from the view of the professional students from Odisha. Further, a higher-order statistical analysis realized the behaviour of the categories. Moreover, the O-RNN predicted the customer retention in maintaining the CSR on FMCG industries. Here, the hidden neurons of RNN were optimized the M-SLnO for minimizing the error among the actual and the predicted outcome, thereby referred as O-RNN. The customer retention with consideration of the impact of CSR activities on FMCG companies and the benefits from CSR was examined in terms of $\mathrm{O}$ RNN and statistical analysis that proved the betterment of the proposed method. From the analysis, the RMSE of the proposed O-RNN for the overall response was $25 \%, 30.77 \%$, $43.75 \%$, and $47.06 \%$ higher than RNN, NN, SVM, and KNN, respectively. Hence, it was clear that the CSR impact on the consumer retention for the FMCG industries returned better prediction responses with the proposed method than all the traditional deep learning algorithms. The performance of the SMAPE is a bit lower than the other methods. This issue will be solved in the future work by developing new variants of automated techniques.

Open Access This article is licensed under a Creative Commons Attribution 4.0 International License, which permits use, sharing, adaptation, distribution and reproduction in any medium or format, as long as you give appropriate credit to the original author(s) and the source, provide a link to the Creative Commons licence, and indicate if changes were made. The images or other third party material in this article are included in the article's Creative Commons licence, unless indicated otherwise in a credit line to the material. If material is not included in the article's Creative Commons licence and your intended use is not permitted by statutory regulation or exceeds the permitted use, you will need to obtain permission directly from the copyright holder. To view a copy of this licence, visit http://creativecomm ons.org/licenses/by/4.0/.

\section{References}

1. Vethirajan C (2017) Societal needs and CSR practices of indian companies: a study with reference to companies in Chennai Region. UGC Research Award Project, pp 301-302

2. Enock ON, Basavaraji K (2013) Corporate social responsibility of tata company and ITC company: a comparative study. Int J Bus Manag Tomorrow (IJBMT) 3(3):1-12

3. Hamann R (2003) Mining companies role in sustainable development: the 'why' and the 'how' of corporate social responsibility from a business perspective. Dev South Afr 20(2):237-254

4. Hohnen P , Potts J (2007) Corporate social responsibility. An implementation guide for business. Int Inst Sustain Dev (IISD) $6(2): 15-31$. 
5. Schüz M (2012) sustainable corporate responsibility: the foundation of successful business in the new millennium. Cent Eur Bus Rev 1(2):7-15

6. Anderson J (1987) Can social responsibility be handled as a corporate investment? Bus Horiz pp 24-25.

7. Carroll AB (1991) The pyramid of corporate social responsibility: toward the moral management of organizational stakeholders. Bus Horiz 34:39-48

8. Brown T, Dacin P (1997) The company and the product: corporate associations and consumer product responses. J Mark 61:68-84

9. Asongu J (2007) The history of corporate social responsibility. J Bus Public Policy 1(3):1-21

10. Baghi I, Rubaltelli E, Tedeschi M (2009) A strategy to communicate corporate social responsibility: cause related marketing and its dark side. Corp Soc Responsib Environ Manag 16(1):15-26

11. Drizin M, Schneider AJ (2004) Understanding the connection between loyalty and profit. Employ Relat Today 30(4):43-54

12. Ieva M, Ziliani C (2018) The role of customer experience touchpoints in driving loyalty intentions in services. TQM J 30(5):444-457

13. Baughn CC, Mcintosh JC (2007) Corporate social and environmental responsibility in Asian countries and other geographical regions. Corp Soc Responsib Environ Manag 14(4):189-205

14. O”berseder M, Schlegelmilch BB, Gruber V (2011) Why don't consumers care about CSR?' A qualitative study exploring the role of CSR in consumption decisions. J Bus Ethics 104(4):449-460

15. Wagner T, Bicen P, Hall ZR (2008) The dark side of retailing: towards a scale of corporate social irresponsibility. Int J Retail Distrib Manag 36(2):124-142

16. Schwartz MS, Carroll AB (2003) Corporate social responsibility: a three-domain approach. Bus Ethics Q 13(4):503-530

17. Megicks P, Memery J, Williams J (2008) Influences on ethical and socially responsible shopping: evidence from the UK grocery sector. J Mark Manag 24(5):637-659

18. Manne R, Kantheti SC (2021) Application of artificial intelligence in healthcare: chances and challenges. Curr J Appl Sci Technol 40(6):78-89

19. Srinivas TAS, Manivannan SS (2020) Prevention of hello flood attack in IoT using combination of deep learning with improved rider optimization algorithm. Comput Commun 163:162-175

20. Ramu C, Vethirajan C (2020) Customers perception of CSR impact on FMCG companies: an analysis. Int J Res Bus Manag 7(3):39-48

21. Shinde S (2014) Study of impact of CSR program on consumer's buying behavior for FMCG products in Mumbai. Abhinav Int Mon Refereed J Res Manag Technol 3(4):67-73
22. Khan S (2009) Corporate social performance of Indian FMCG companies introduction of CSR, framework and Karmayog CSR ratings with three top Indian FMCG companies CSR initiatives. Issues Soc Environ Account 3(2): 180-201

23. Sanclemente-Téllez JC (2017) Marketing and Corporate Social Responsibility (CSR). Moving between broadening the concept of marketing and social factors as a marketing strategy. Span J Mark ESIC 21(1):4-25

24. Amin-Chaudhry A (2016) Corporate social responsibility: from a mere concept to an expected business practice. Soc Responsib J 12(1):190-207

25. Sundström M, Hjelm-Lidholm S (2019) Re-positioning customer loyalty in a fast moving consumer goods market. Austral Mark J. https://doi.org/10.1016/j.ausmj.2019.09.004

26. Jaiswal N, Gautam A (2016) Corporate social responsibility: entrepreneurial initiatives of Indian FMCG industry. SMS J Entrep Innov. https://doi.org/10.21844/smsjei.v2i2.11140

27. Öberseder M, Schlegelmilch BB, Murphy P (2013) Consumers' perceptions of corporate social responsibility: scale development and validation. J Bus Ethics 124(1):101-115

28. Agrawal S (2020) A study to measure the dimensions of CSR in FMCG companies. Appl AHP Model 9(5):984-997.

29. Hanke T, Stark W (2009) Strategy development: conceptual framework on corporate social responsibility. J Bus Ethics 85(3):507-516

30. Li F, Liu M (2019) A hybrid convolutional and recurrent neural network for hippocampus analysis in Alzheimer's disease. J Neurosci Methods 323:108-118

31. Masadeh R, Mahafzah BA, Sharieh A (2019) Sea Lion Optimization Algorithm. Int J Adv Comput Sci Appl. https://doi.org/10.14 569/IJACSA.2019.0100548

32. Swamy SM, Rajakumar BR, Valarmathi IR (2013) Design of hybrid wind and photovoltaic power system using opposition-based genetic algorithm with cauchy mutation. In: IET Chennai Fourth International Conference on Sustainable Energy and Intelligent Systems (SEISCON 2013), Chennai, India

33. Rajakumar BR, George A (2012) A new adaptive mutation technique for genetic algorithm. In Proceedings of IEEE International Conference on Computational Intelligence and Computing Research (ICCIC), Coimbatore, India, pp 1-7

Publisher's Note Springer Nature remains neutral with regard to jurisdictional claims in published maps and institutional affiliations. 